no significant difference has been found between survival in the two groups in clinical stage I cases, those with stage II tumours showed a statistically better survival in the radical mastectomy group at 10 years, though this was not seen after 5 years. A significantly greater rate of local recurrence was observed in the tylectomy group than in those undergoing radical mastectomy, but there was a higher incidence of lymphoedema of the arm in the radical mastectomy group.

Only when all the permutations and combinations of treatments carried out in various centres on patients with breast cancer have been submitted to such thoroughly controlled investigation will surgeons be in a position to judge the best possible treatment for an individual patient with this disease.

\footnotetext{
1 Halsted, W. S., Annals of Surgery, 1894, 20, 497.

2 Forrest, A. P. M., British fournal of Surgery, 1969, 56, 782

3 Johnstone, F. R C., Surgery, Gynecology and Obstetrics, 1972, 134, 211

4 Galasko, C. S. B., Annals of the Royal College of Surgeons of England, $1972,50,3$.

Bloom, H. J. G., in Prognostic Factors in Breast Cancer, ed. A. P. M. Forrest and P. B. Kunkler, p. 3. London, Livingstone, 1968.

Kaae, S., and Johansen, H., in Prognostic Factors in Breast Cancer, ed. A. P. M. Forrest and P. B. Kunkler, p. 93. London, Livingstone, 1968. Fisher, B., in Surgery Annual, 1971, 3, p. 227, ed. P. Cooper and L. M. Nyhus. New York, Appleton, 1971 .
}

\section{Nutrition and Sleep}

"Very extraordinary boy. . . . Goes on errands fast asleep, and snores as he waits at table . . . a wonderfully fat boy." Charles Dickens penned the first description of the Pickwickian syndrome, a syndrome that provides one of many intriguing links between nutrition and sleep. Though patients suffering from it may be improved by dieting their basic disorder is a neurophysiological one that gives rise to overeating, to daytime sleepiness, and to characteristic nocturnal sleep made up of an endless sequence of apnoea, abortive grunts, and explosive snorts. ${ }^{1-3}$

Overpowering sleepiness is also a feature of the more common narcoleptic syndrome. In some patients the onset of this disorder is abrupt and is then often associated with a rapid gain in weight. ${ }^{4}$ The obesity is secondary, and slimming improves neither the attacks of sleepiness nor the cataplectic episodes characterized by loss of muscle tone. Yet another association between sleepiness and nutrition is found in examples of the Kleine-Levin syndrome, in which periods of days or weeks of inertia are associated with voracious eating. ${ }^{56}$ In contrast are the effects of the amphetamine derivatives used for appetite and weight reduction, all of which, even diethvlprovion ${ }^{7}$ and fenfluramine, ${ }^{8}$ may cause reduced or restless sleep. Severe weight loss and restlessness are also features of anorexia nervosa, and A. H. Crisp 9 drew attention to the poor sleep of these patients and proposed that insomnia in this and other psychiatric disorders might have a nutritional origin and not just an anxiety basis. It may be noted that rats kept without food sleep less and less and become totally insomniac after six to eleven days. ${ }^{10}$

Recently Crisp and his colleagues ${ }^{11}$ studied the sleep of patients with anorexia nervosa before and after treatment. After refeeding for six to twelve weeks the patient spent significantly less time awake or drowsy in the night, and the E.E.G. stage of sleep, characterized by the largest electrical slow waves and usually called stage 4 sleep, greatly increased. This stage of sleep has a number of known metabolic associations: it is enhanced by thyroid hormone, 12 has been found to be increased after exercise in trained athletes, ${ }^{13}$ and seems to govern nocturnal growth hormone secretion $^{14}{ }^{15}$-all of which suggest an anabolic and restorative role for this stage of sleep.

A glass of hot milk is a traditional remedy for sleeplessness. Relaxation arising from warmth, a childlike feeling of being pampered, or alternatively a response to the consummation of a basic drive may explain this. It is commonly believed that a good meal or coitus lead to sleepiness, and certainly male rats sleep much more after sexual activity. ${ }^{16}$ But a more specific response is suggested by the work of J. W. Fara and colleagues. ${ }^{17}$ They found that the introduction into the duodenum of fat in the form of milk or corn oil enhanced sleep in cats, and from this they suggested that a gastrointestinal hormone could be responsible for promoting sleep. The authors of the papers printed at pages 429 and 431 of this journal report that their investigations, though they used different methods, show that sleep is less restless or less broken after a bedtime hot milk-cereal beverage that for many years has been claimed to improve sleep. The apparent effect of the drug was greatest in the latter part of the night. In an era of heavy prescribing of hypnotic drugs this is a welcome finding.

The dearth of knowledge about digestive and metabolic processes during the large part of our lives we spend asleep emphasizes the need for further research.

\footnotetext{
Schwartz, B. A., Seguy, M., and Escande, J.-P., Revue Neurologique, $1967,117,145$

Kuhlo, W., Archiv für Psychiatrie und Zeitschrift f. d. ges. Neurologie, 1968, 211, 170

Hishikawa, Y., Furuya, E., and Wakamatsu, H., Folia Psychiatrica et Neurologica f̆anonica, 1970, 24, 164.

Daniels, L. E., Medicine (Baltimore), 1934, 13, 1.

Critchley, M., Brain, 1962, 85, 627.

- Garland, H., Sumner, D., and Fourman, P., Neurologv, 1965, 15, 1161

Oswald, I., Iones, H. S., and Mannerheim, J. E., British Medical Journal, $1968,1,796$.

Lewis, S. A., Oswald, I., and Dunleavy, D. L. F., British Medical Fournal, $1971,3,67$.

- Crisv, A. H., Fournal of Psychosomatic Research, 1967, 11, 117.

10 Jacobs, B. L., and McGinty, D. J., Experimental Neurology, 1971, 30, 212. Crisp, A. H., Stonehill, E., and Fenton, G. W., Postgraduate Medical Fournal, 1971, 47, 207.

2 Kales, A., et al., fournal of Clinical Endocrinology and Metabolism, 1967, 27,1593

${ }^{13}$ Baekeland, F., and Lasky, R., Perceptual and Motor Skills, 1966, 23, 1203.

14 Sassin, I. F., et al., Science, 1969, 165, 513.

15 Sassin, J. F., et al. Life Sciences, 1969, 8, Part 1, No. 23, p. 1299.

16 Boland, B. D., and Dewsbury, D. A., Physiology and Behaviour, 1971, 6, 145, B. D., and Dewsbury, D. A., Physiology and Behaviour, 1971, 6,

17 Fara, J. W., Rubinstein, E. H., and Sonnenschein, R. R., Science, 1969, 166, 110 .
}

\section{Analgesia for Burnt Patients: A Symposium}

Ever since man discovered fire he has been liable to injury by burning. The advance of civilization, particularly since the Industrial Revolution, has increased this liability owing to the growing use of electricity, gas, and chemicals as well as fire. Innumerable attempts have been made to control the pain associated with it, but until recent years they have been largely unsuccessful owing to the difficulty of applying effective analgesia without disturbing the feeding pattern of the patient.

The establishment and increasing technical refinement 
of burns centres, first in Britain and then throughout the world, has allowed more concentrated attacks to be made on the multitude of problems associated with the treatment of the severely burned patient. These burns centres, by attracting such patients, have disclosed the vast range of metabolic problems which are little understood, and have produced more interest and co-operation between members of different specialties. It is being increasingly recognized that the anaesthetist has an important role in the solution of these problems. The skilled use of general anaesthesia, and the use of suitable analgesics for the relief of pain during burns dressings, are receiving more attention from anaesthetists interested in the complex psychological and metabolic derangements to which the severely burnt patient is subject. Nevertheless, it is regrettable that only very few burns centres in the world have the services of a full-time anaesthetist.

Evidence of the anaesthetists' growing concern about the problems they meet in the treatment of burnt patients was shown by the success of a recent symposium. It was held at the Queen Victoria Hospital, East Grinstead, in October 1971, and its proceedings have now been published. ${ }^{1}$ It considered "The Place of the Anaesthetist in the Treatment of the Burnt Patient." The meeting was apparently the first of its kind in any country and was attended mainly by anaesthetists (together with a small number of physicians and surgeons) from Britain, but with participants from Australia, Belgium, Canada, Holland, and Jugoslavia. Its proceedings show that a more rational approach to treatment has become possible because of growing success in the control of pain.

The symposium was divided into two sessions. The first of these was devoted primarily to the problem of the control of pain of the burns dressing. Being a pioneer meeting, the meaning of the term "burns dressing" had to be discussed, for it is subiect to many interpretations, ranging in one hospital from the removal of bandages and underlying dressings to extencive surgical procedures such as the taking of solit skin grafts. But uniformity of definition is proving difficult to obtain. The first Daper reviewed the history of analgesic methods used for the burnt patient. The number of remedies invoked over the centuries are a testimony to the confusion and loose thinking associated with this problem. It would appear that not until the late 1940s were techniques evolved which could offer effective analgecia without disturbing the patient's feeding pattern. ${ }^{2} 3$ At this time also it began to be aporeciated that the complete control of pain, as well as being an obvious goal in itself, also contributed handsomely to the general physical and psychological wellbeing of the patient.

The effectiveness of "neuroleptanalgesia"- a combination of droperidol and phenoperidine-in the control of pain, was reported in 1966.4 This technique, modified by the addition of Entonox, was reported on by P. J. F. Baskett in this symoosium. A further procedure was reported on by K. J. Packer-a continuation of previously described work with methoxyfluorane. ${ }^{5}$ This rebort drew attention to recent advances - namely, ranid recovery after the administration of the drug, total elimination of the pre- and postoperative fasting, the absence of vomiting, and some postoperative analgesia. This speaker underlined the ultimate aim of the treatment of the burnt patient-c"To return an economically indenendent individual to the community." Both this speaker and others voiced their concern at the reports that methoxyfluorane had a nephrotoxic effect, ${ }^{6}$ for if they are con- firmed they will probably lead to the removal of an unequalled inhalation drug from the anaesthetists' armamentarium. However, it would appear that the nephrotoxic effect of methoxyfluorane is related to the dose used, to the frequency of its administration, and to the simultaneous use of other drugs-for example, tetracycline. ${ }^{7}$

The second session of the symposium was devoted to reports and discussion of the complex biochemical changes which occur in the burnt patient. They are assuming greater importance as the surgical problems associated with the burn wound are being overcome. A physician specializing in this field described her experience in treating these metabolic disturbances and outlined future trends and problems. The final papers were on the general as well as the specific problems of anaesthesia in both the burnt child and the burnt adult. It was reassuring to hear reiterated the warnings about administering succinylcholine to burnt patients and to learn of the continued usefulness of wellestablished agents such as trichlorethylene. Finally, the use of ketamine both as an analgesic and an anaesthetic for full surgical procedures was discussed, including the terrifying dreams it may cause.

Much useful information was disseminated at this symposium, and its aims were largely fulfilled. The nature of the problems were clarified, and a focal point for future discussions established. A second symposium is to be held in Edinburgh in 1973, and it is hoped that further support by those interested in the treatment of the burnt patient will be forthcoming.

1 Postgraduate Medical 7ournal, 1972, 48, 123.

2 Gordon. R. A., Canadian Medical Association fournal, 1943, 49, 478. Visser, E. R., and Farrow. A. B., Anesthesia and Analgesia-Current Researches, $1959,38,301$.

4 Smith. B. G., and Hollis, D. A., British fou'nal of Anaesthesia, $966,38,471$

Packer. K. J., and Titel, J. H., British fournal of Anaesthesia, 1969,

Mazze, R. I., Shue, G. L., and Tackson, S. H., Fournal of the American Medical Association, 1971, 216, 278.

Proctor. A. E., and Barton, S. L., British Medical fournal, 1971, 4, 661 .

\section{Mothering the Baby}

Two years ago a leading article in this journal ${ }^{1}$ stated: "In Britain it seems natural and normal for a mother in a maternity hospital to have her full-term baby not in a nursery but at her bedside, so that she can admire him, gloat over him, show him off, and display his beauty, pick him up, cuddle him, and feed him as soon as he cries from hunger." But American journals continue to publish studies of "rooming in" and of the effect of handling the newborn baby. In a Californian study ${ }^{2}$ in which 41 mothers were allowed to handle and later feed their babies all but two mothers thought that the idea was a good one.

Now a Cleveland group ${ }^{3}$ has set out to determine whether present practices with regard to the care of the newborn may influence later behaviour. The Cleveland workers wrote that "In most nurseries in the United States, however, even full-term mothers are separated from their infants for a short, but possibly important time." They allowed 14 mothers of normal full-term babies, acting as controls, to have "traditional contact with their infants: a glimpse of the baby shortly after birth, brief contact and identification at six to 12 hours, and then visits for 20 to 30 minutes every 